\title{
PROPOSIÇÃO DE UMA METODOLOGIA ESTRUTURADA DE AVALIAÇÃO DO POTENCIAL REGIONAL DE REÚSO DE ÁGUA: 04 - DESAFIOS TENDÊNCIAS
}

\author{
TOWARDS A STRUCTURED METHODOLOGY FOR ASSESSING REGIONAL WATER REUSE \\ POTENTIAL: 04 - CHALLENGES AND TRENDS
}
Maíra Araújo de Mendonça Limaa, Ana Silvia Pereira Santosa, Pablo da Silva Avelarb, Luis Carlos Soares da Silva Junior ${ }^{c}$, Bruna Magalhães de Araujod, Ricardo Franci Gonçalvese, José Manuel Pereira Vieiraf.
aUniversidade do Estado do Rio de Janeiro, ${ }^{b}$ Empresa Baiana de Água e Saneamento, ' Universidade Federal do Rio de

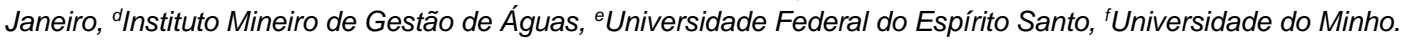

mairalima.90@gmail.com,ana.pereira@ueri.br,.pablo.avelar@embasa.ba.gov.br,luis.junior@coc.ufr..br. brunamagalhaes5@gmail.com,rfg822@gmail.com,jvieira@civil.uminho.pt

Submissão: 05 de março de 2021 Aceitação: 1 de julho de 2021

\section{Resumo}

Na sequência do conteúdo apresentado pelas Notas Técnicas 01,02 e 03, a presente tem como objetivo elencar e discutir os diversos desafios e tendências sobre a aplicação, sistematização e institucionalização da prática de reúso de água no Brasil. Em linhas gerais, a própria condição brasileira de país em desenvolvimento já carrega uma série de desafios relacionados diretamente à prestação de serviços de saneamento e, consequentemente, ao reúso de água. No diálogo internacional, mais avançado, os desafios e tendências são ainda mais proeminentes e, nesse contexto, o Brasil ainda precisa vencer etapas internas de desenvolvimento, mudança de paradigma e modernização do setor para alcançar os objetivos de reúso de maneira segura e responsável, preservando o meio ambiente, os recursos hídricos e a saúde da população. Muitos desses desafios internos podem ser transpostos por meio de implantação e operação de projeto piloto anteriormente à instalação do empreendimento definitivo de reúso e da conscientização de todos os envolvidos, tais como gestores e tomadores de decisão, operadores de sistemas de reúso de água e a sociedade civil como um todo. Essa conscientização pode ser aplicada em contexto de capacitação continuada, com objetivo de transformação e estabelecimento de uma cultura de uso racional e reúso de água, inclusive com a abordagem do projeto piloto como objeto dessa transformação.

Palavras-chave: capacitação continuada; tomadores de decisão; operadores; sociedade civil; projeto piloto.

\section{Abstract}

Following the content presented in Technical Notes 01,02 , and 03 , the purpose of this TN is to list and discuss the several challenges and trends regarding the practice of water reuse application, systematization, and institutionalization in Brazil. In general terms, the developing country label that Brazil carries poses a series of challenges directly linked to providing sanitation services and, therefore, to water reuse. The international dialogue, in a more mature context, the challenges and trends outstand more even more. Thus, Brazil still needs to overcome internal stages of development, paradigm changes, and modernization of the sector, to achieve the goal of safe and responsible reuse while preserving the environment, water resources, and public health. Many of these internal challenges are achievable through pilot project implementation and operation before establishing the permanent reuse enterprise. Another challenge is raising the consciousness of all those involved, such as managers and decision-makers, operators of water reuse systems, and civil society itself. This consciousness-raising can be applied in the context of continuous training, with the objective of 
transformation and establishment of a culture of rational use and water reuse, including the pilot project as a driver of this transformation.

Keywords: capacity building; decision makers; operators; civil society; pilot project.

\section{INTRODUÇÃO}

Conforme já discutido no conjunto de Notas Técnicas referentes à "proposição de uma metodologia estruturada de avaliação do potencial regional de reúso de água", a reutilização planejada de água a partir de efluente tratado é uma prática crescente em todo o mundo. Visa-se com isso, uma gestão mais eficiente da água em regiões com diferentes níveis de escassez hídrica, ou até mesmo naquelas em que é realizado o planejamento dos recursos de maneira mais ampla, como forma de alavancar 0 desenvolvimento de suas atividades. A adoção do reúso de água planejado propicia um equilíbrio entre a demanda e a oferta de água para diferentes fins, a longo prazo, e minimiza os impactos no meio ambiente a partir da redução do lançamento de efluentes nos mananciais e da redução da captação de água bruta. Assim, indubitavelmente, a prática de reúso é uma alternativa de preservação dos recursos hídricos, do meio ambiente, e uma ferramenta de impulsionamento do desenvolvimento socioeconômico (SANTOS et al., 2018; ARENA et al., 2020). No entanto, Angelakis et al. (2018) ressaltam que ainda há muitos desafios a vencer de forma a tornar o reúso de água uma prática segura e institucionalizada nas regiões mais afetadas pela seca.

No Brasil, muitos impasses ainda são preponderantes no caminho para a sistematização da prática de reúso: i) baixos índices de atendimento aos serviços de coleta e tratamento de esgotos sanitários, que refletem na reduzida produção de água de reúso; ii) baixa qualidade operacional das Estações de Tratamento de Esgotos (ETE), que muitas vezes impede 0 alcance do desempenho desejado; iii) cultura histórica de percepção de abundância de água, que reflete no descaso do usuário em relação ao reúso e ao uso racional de água, além de contribuir para a rejeição psicológica do produto; iv) ausência de um documento legal, a nível federal, que regulamente a prática de reúso de água com o estabelecimento de padrões para diferentes fins (conforme apresentado na NT01); v) entraves burocráticos para 0 desenvolvimento e financiamento de projetos específicos para este fim (descritos com maiores detalhes na NT02); vi) falta de estudos técnico-científicos de viabilidade de implantação de projetos de reúso de água e ausência de formação de recursos humanos capacitados para lidar com esses projetos de reúso de água; vii) falta de segurança em relação aos riscos epidemiológicos intrínsecos à pratica, em função das dificuldades de aplicação de metodologias (quantitativa, semiquantitativa e qualitativa) de risco microbiológico; viii) utilização de dados estimados para cálculos de potencialidades, em detrimento ao uso de dados reais, devido à falta de transparência das operadoras de água e esgoto (apresentado na NT03); entre outros.

Os projetos de reúso de água demandam um esforço conjunto de diferentes setores no sentido de favorecer o seu estabelecimento de maneira segura e com o real objetivo de atender às expectativas de quantidade, qualidade e suprimento das demandas pretendidas. Assim, o tema "reúso de água" se caracteriza como uma área de conhecimento emergente no Brasil, com características multi e interdisciplinares, que carece de capacitação continuada para todos os níveis hierárquicos, desde os tomadores de decisão, até aos operadores (produtores e consumidores) dos sistemas, passando pela sociedade civil, que é diretamente afetada pelos projetos de reúso de água.

Conforme descrito na NT02, na administração pública, que é a principal forma de administração de sistemas de esgotamento sanitário e abastecimento de água no país, há um longo caminho a ser seguido no processo de implantação e operação de projetos de reúso. Apesar de a área técnica ter plena capacidade de esclarecer, apontar e definir, com alguma facilidade, a localização das ofertas e a localização das demandas de água de reúso, o sistema de gestão, que muitas vezes se apresenta ineficiente, impede o planejamento e a alocação de recursos para o desenvolvimento do projeto. De maneira simples, conforme já destacado na NT03, a localização das ofertas refere-se basicamente às ETEs, enquanto a localização das demandas refere-se às áreas de conflito pelo uso da água, regiões de escassez em diferentes níveis e regiões 
com demandas

impulsionamento

socioeconômico.

No caso da oferta da água de reúso, há que se destacar a necessidade de avaliação da relação entre quantidade, qualidade e usos pretendidos. A abordagem de qualidade fit-for-purpose (ou ajustada para o uso), conforme propõe ISO (2020) e APA (2019), indica que as características físicoquímicas e microbiológicas da água de reúso, de acordo com padrões de qualidade de água, devem ser alcançadas conforme o uso pretendido (OMS, 2016). Há assim que se atentar para imposições desnecessariamente muito restritivas para usos que não demandam elevada qualidade. Esse caso, pode acabar por restringir a prática em vez de fomentá-la, conforme amplamente discutido na NT01, que abordou os aspectos nacionais de regulamentação, alertando inclusive para a falta de coerência entre os padrões já estabelecidos no país (federais não mandatórios e sub-federais mandatórios). Sobre a demanda de água de reúso, a gestão regional, seja ela municipal, estadual, federal ou até mesmo ao nível de bacia hidrográfica, deve mapear as áreas mais carentes de água, como fator de planejamento, tanto para minimizar os impactos de escassez hídrica e de conflitos pelo uso da água, como para fomentar o desenvolvimento socioeconômico.

No Brasil, historicamente, as ETEs, que nesse contexto representam a oferta de água de reúso, são geridas pela "gestão de saneamento", enquanto os aspectos de demanda de água são administrados pela "gestão de recursos hídricos". É no contexto atual da nova lei do saneamento no Brasil (Lei 14.026/2020) que a gestão de saneamento passa a ser integrada à gestão de recursos hídricos (BRASIL, 2020), de forma a caminhar na direção do conceito da água como sendo uma só (one water). O estabelecimento desse paradigma é um dos principais desafios propostos por Angelakis et al. (2018).

Ainda em se tratando do conhecimento técnico, o levantamento das potencialidades regionais para implantação do reúso de água deve abordar, além dos fatores mencionados anteriormente (localização das ofertas e localização das demandas), a avaliação de distâncias entre ofertas e demandas, a listagem de áreas prioritárias, estudo preliminar de custo e a produção de mapas, destacados com maiores detalhes na NT03. O conjunto de todos esses fatores proporcionam o incremento e a robustez do estudo de potencialidades tão discutido nesse conjunto de Notas Técnicas, servindo de ferramenta essencial para as tomadas de decisão.

Mediante finalização dos estudos de potencial, Mukejeree e Jansen (2020) destacam como desafio a implantação e operação de projetos piloto de reúso de água, anteriormente à condução do empreendimento definitivo, de forma a produzir experiência e resultados transparentes, inclusive com o objetivo de conquistar o usuário para minimizar os impactos da rejeição. A viabilidade do projeto final pode estar em causa, a partir de uma adequada condução ou não de um projeto piloto. Os mesmos autores destacam a operação de projetos piloto com duração de até 10 anos.

O conjunto das Notas Técnicas (NT), perfazendo quatro conteúdos, tem como principal objetivo a proposição de uma metodologia estruturada de avaliação do potencial regional de reúso de água no Brasil. Seu foco principal é a inserção dessa fonte alternativa na matriz hídrica regional dentro do território nacional, de forma a propiciar o avanço do planejamento dos recursos hídricos e saneamento, como também auxiliar gestores e tomadores de decisão. A Nota Técnica (NT04), última do conjunto apresentado, aborda os problemas e os desafios enfrentados tanto para a elaboração como para a finalização do diagnóstico do potencial de reúso de água para a materialização do projeto piloto e dos empreendimentos futuros na região de estudo.

\section{DESAFIOS E TENDÊNCIAS}

Os principais desafios relacionados à prática de reúso de água no Brasil estão agrupados e discutidos no Quadro 1. Por ser um país com características bastante peculiares, esses desafios devem ser internalizados de forma a permitir o avanço da prática no território nacional e a evolução/ desenvolvimento de uma experiência particular, com o objetivo de evitar erros já ocorridos no passado em outras regiões. Pelo fato de o Brasil estar atrasado em relação a outras nações do mundo no aspecto de sistematização da prática de reúso, as experiências internacionais devem ser tomadas como exemplo, mas não como eixo principal da condução do processo. A solução dos problemas se faz principalmente com a criação de uma cultura de reúso de água no país, que perpassa um processo educacional longo e desafiador.

As dificuldades e os obstáculos impostos ao cenário nacional (Quadro 1), por si só já 
representam um grande desafio. Entretanto, no cenário internacional são apresentados outros, além de tendências demasiadamente mais avançadas, conforme destacado por Angelakis et al. (2018):

\section{Quadro 1: Desafios e características para a institucionalização da prática de reúso de água no Brasil}

\begin{tabular}{|c|c|c|}
\hline & Desafio & Descrição \\
\hline 1 & $\begin{array}{l}\text { Baixos índices de } \\
\text { atendimento aos } \\
\text { serviços de coleta e } \\
\text { tratamento de } \\
\text { esgotos sanitários }\end{array}$ & $\begin{array}{l}\text { De acordo com ANA (2020a), o índice de tratamento de esgotos no Brasil é abaixo } \\
\text { de } 50 \% \text { em relação ao esgoto gerado. Na medida em que a prática de reúso depende } \\
\text { diretamente da disponibilidade de esgoto tratado, Lima et al. (2020) e Melo et al. } \\
\text { (2020) afirmam que áreas com elevadas demandas de água de reúso, apesar do } \\
\text { potencial, podem não ser contempladas em função dos seus baixos índices de } \\
\text { tratamento de esgoto. Nesse sentido, um aspecto relevante é o vislumbre de } \\
\text { desenvolvimento de novos projetos de ETE já em consonância com as demandas } \\
\text { por reúso de água, no caminho da universalização (LIMA et al., 2020). }\end{array}$ \\
\hline 2 & $\begin{array}{l}\text { Baixa qualidade } \\
\text { operacional das } \\
\text { ETEs }\end{array}$ & $\begin{array}{l}\text { A prática de reúso de água bem-sucedida é diretamente relacionada à qualidade do } \\
\text { efluente produzido na ETE e/ou na Estação Produtora de Água de Reúso (EPAR). } \\
\text { Entretanto o desempenho operacional esperado para as ETEs em todo o território } \\
\text { nacional nem sempre é alcançado. Para se alcançar esse desempenho, o eixo } \\
\text { concepção-projeto-implantação-operação deve ser alinhado e bem conduzido } \\
\text { (MORAES et al., 2020; ESPINOSA et al., 2017). Não raro, no Brasil, os projetos de } \\
\text { ETE são realizados sem concepção adequada, e etapas construtivas e operacionais } \\
\text { inadequadas (CHERNICHARO et al., 2018). Muitas obras são implantadas com } \\
\text { projetos básicos e os baixos recursos financeiros aplicados levam a materiais e } \\
\text { equipamentos de mais baixa qualidade, gerando instabilidades e sérios problemas } \\
\text { operacionais. Ainda, em geral, o monitoramento da qualidade do efluente não é } \\
\text { alinhado com as práticas operacionais e muitas vezes não representa o desempenho } \\
\text { real da ETE. Neste caso, os regulamentos de reúso devem ser bastante rígidos em } \\
\text { relação ao monitoramento, com fiscalização adequada, de forma a garantir a } \\
\text { segurança da prática. }\end{array}$ \\
\hline 3 & $\begin{array}{l}\text { Cultura histórica de } \\
\text { percepção de } \\
\text { abundância de } \\
\text { água }\end{array}$ & $\begin{array}{l}\text { Apesar de o Brasil ser o país detentor da maior quantidade de água (13\%) no mundo } \\
\text { (ANA, 2020a), ela está distribuída de maneira desigual em todo o território nacional: } \\
\text { regiões com abundância de água têm o menor contingente populacional e, de } \\
\text { maneira oposta, regiões com menor disponibilidade hídrica têm altas densidades } \\
\text { populacionais. Outro aspecto relevante é a região do Semiárido, predominantemente } \\
\text { contida na região Nordeste, que apresenta escassez crônica devido aos baixos } \\
\text { índices pluviométricos, altos índices de evaporação e rios intermitentes. Mas, ainda } \\
\text { assim, é nesse contexto que se criou uma cultura de percepção de excesso de água, } \\
\text { que traz sérios desafios para a implantação de projetos de reúso e uso racional de } \\
\text { água em todo o país. A gestão de recursos hídricos e saneamento no Brasil, inclusive } \\
\text { a nível regional (estadual e municipal), deve considerar esse aspecto e levantar a } \\
\text { absoluta necessidade de conscientização e de transformação desse cenário. } \\
\text { Segundo WE (2020), somente com uma sociedade inteligente em termos de água } \\
\text { (Water Smart Society), será possível conviver com os problemas de escassez hídrica } \\
\text { decorrentes das mudanças climáticas e do crescimento populacional no mundo. }\end{array}$ \\
\hline 4 & $\begin{array}{l}\text { Ausência de } \\
\text { regulamentação } \\
\text { federal sobre reúso } \\
\text { de água com o } \\
\text { estabelecimento de } \\
\text { padrões para } \\
\text { diferentes fins }\end{array}$ & $\begin{array}{l}\text { Conforme discutido na NT01, um dos principais problemas relacionados às } \\
\text { dificuldades de desenvolvimento da prática de reúso no Brasil é a ausência de } \\
\text { regulamentação a nível federal e a incompatibilidade entre os padrões estabelecidos } \\
\text { pelos regulamentos sub-federais no país (SANTOS et al., 2020). Angelakis et al. } \\
\text { (2018) corroboram essa afirmação, destacando que mesmo de maneira global, } \\
\text { apesar da grande quantidade de documentos reguladores já publicados em diversas } \\
\text { regiões do planeta, existe pouca padronização em todo o mundo. Assim, em um país } \\
\text { com dimensões continentais como o Brasil, é importante que sejam estabelecidos } \\
\text { padrões de requisito mínimos e coerentes para a prática de reúso em documentos } \\
\text { reguladores, para proteção da saúde, do meio ambiente e da economia nacional no } \\
\text { futuro. É necessário ainda o desenvolvimento de soluções abrangentes e flexíveis, } \\
\text { além de um quadro regulatório aliado a uma política de reúso de água eficiente com } \\
\text { base em avaliações mais realistas de risco, para que a prática possa ser aplicada de } \\
\text { forma segura, responsável e sistêmica. }\end{array}$ \\
\hline
\end{tabular}




\begin{tabular}{|c|c|c|}
\hline & Desafio & Descrição \\
\hline 5 & $\begin{array}{l}\text { Entraves } \\
\text { burocráticos para o } \\
\text { desenvolvimento e } \\
\text { financiamento de } \\
\text { projetos de reúso }\end{array}$ & $\begin{array}{l}\text { A administração pública no Brasil é conhecida por apresentar diversos entraves } \\
\text { burocráticos, conforme destacado na NT02. No caso do desenvolvimento de projetos } \\
\text { de potencialidades e de implantação de empreendimentos de reúso de água, deve } \\
\text { haver flexibilização baseada em estudos técnico-científicos que garantam a } \\
\text { segurança e a eficácia da prática. Conforme estabelecido por Brasil (2020), a ANA } \\
\text { passa a ser responsável pela criação de normas de referência no setor saneamento, } \\
\text { e nesse sentido, deverá propor documentos flexíveis e menos burocráticos para } \\
\text { favorecer a sistematização da prática. }\end{array}$ \\
\hline 6 & $\begin{array}{l}\text { Falta de estudos } \\
\text { técnico-científicos } \\
\text { de viabilidade de } \\
\text { implantação de } \\
\text { projetos de reúso } \\
\text { de água }\end{array}$ & $\begin{array}{l}\text { As decisões técnico-políticas devem ser tomadas com base em estudos técnico- } \\
\text { científicos, que garantam o desempenho, a eficácia e a segurança dos } \\
\text { empreendimentos de reúso de água. Metodologias de avaliação de potencialidades } \\
\text { já publicadas em diversos estudos (LIMA et al., 2020; MELO et al., 2020; ARAUJO } \\
\text { et al., 2017) podem ser replicadas para as regiões específicas de forma a auxiliar o } \\
\text { desenvolvimento dos projetos. Convênios entre as instituições de ensino e pesquisa } \\
\text { que desenvolvem estudos de reúso de água no Brasil devem ser firmados com } \\
\text { companhias de saneamento e órgãos reguladores que pretendem avançar no tema, } \\
\text { inclusive como forma de capacitar recursos humanos para lidar com os projetos } \\
\text { implantados. No entanto, no Brasil, historicamente a relação desses órgãos com a } \\
\text { academia, em geral é desgastada e pouco sólida. Esse alinhamento é fundamental } \\
\text { para o desenvolvimento, institucionalização e sistematização da prática de reúso no } \\
\text { Brasil. }\end{array}$ \\
\hline 7 & $\begin{array}{l}\text { Insegurança em } \\
\text { relação aos riscos } \\
\text { epidemiológicos }\end{array}$ & $\begin{array}{l}\text { A prática de reúso de água, por utilizar efluente tratado com consideráveis } \\
\text { densidades de organismos patogênicos, envolve, naturalmente, o risco de } \\
\text { contaminação microbiológica (ISO, 2020; BASTOS et al., 2008). Essa contaminação } \\
\text { pode ocorrer por vias de ingestão, adsorção dérmica ou inalação e, de acordo com } \\
\text { o fim adotado no reúso de água, essas vias oferecem maiores ou menores riscos } \\
\text { (OMS, 2016). Dessa forma, a avaliação de risco deve ser necessariamente incluída } \\
\text { como instrumento de viabilidade técnica dos empreendimentos de reúso (ISO, 2020; } \\
\text { APA, 2019). Apesar de a OMS propor a metodologia de Avaliação Quantitativa de } \\
\text { Risco Microbiológico (AQRM), essa é de grande complexidade e indicada para água } \\
\text { de abastecimento e reúso potável. No caso do Brasil, que ainda não apresentou } \\
\text { potencial elevado de reúso potável, as metodologias mais simplificadas, como } \\
\text { semiquantitativa (ISO, 2020; APA, 2019) e qualitativa (APA, 2019) podem ser mais } \\
\text { adequadas. }\end{array}$ \\
\hline 8 & $\begin{array}{l}\text { Falta de } \\
\text { transparência das } \\
\text { companhias de } \\
\text { água e esgoto }\end{array}$ & $\begin{array}{l}\text { O sucesso dos projetos de reúso dependem integralmente de uma relação sólida e } \\
\text { de confiança entre as instituições que oferecem a água de reúso e o usuário } \\
\text { (MUKEJEREE e JANSEM, 2020). Em geral, as companhias de saneamento e } \\
\text { demais instituições similares que fornecem os serviços de água e esgoto, são as que } \\
\text { também ofertam a água de reúso. No entanto, por falta de transparência, as relações } \\
\text { entre essas instituições e o possível consumidor da água de reúso são bastante } \\
\text { desgastadas no país. Essas instituições protagonizam, com frequência, episódios } \\
\text { que geram desconfiança, como descarte de esgoto bruto nos corpos hídricos, } \\
\text { distribuição de água de abastecimento contaminada, cobrança de tarifa de } \\
\text { esgotamento sanitário para regiões que não são abrangidas por esse serviço etc. } \\
\text { Dessa forma, é fortemente recomendado que as empresas responsáveis pela } \\
\text { produção da água de reúso trabalhem exaustivamente na construção de uma relação } \\
\text { de confiança mais sólida com os seus usuários em geral. }\end{array}$ \\
\hline
\end{tabular}

- Reúso potável de água (direto ou indireto), que apesar de não ser uma prática disseminada no Brasil, já é realidade em vários países do mundo e é destacado por Angelakis et al. (2018) como sendo a principal tendência sobre o tema "reúso de água", nomeadamente nos grandes centros urbanos. O reúso potável indireto, de maneira planejada, é aplicado em muitas regiões do mundo, como Estados Unidos (MUKEJEREE e JANSEM, 2020), Austrália (KHAN e ANDERSON, 2018), Bélgica (FRIJNS et al., 2016), Inglaterra (SANCHEZ-FLORES et al., 2016) e Singapura (HARTLEY et al., 2019; LEFEBVRE, 2018). Já o reúso potável direto é mais restrito e se apresenta também nos Estados Unidos (MUKEJEREE e JANSEM, 
2020), além da África do Sul (LAHNSTEINER et al., 2019) e da Namíbia (HARTLEY et al., 2019). Inclusive, a Namíbia apresenta o principal caso de sucesso no mundo com essa modalidade de reúso de água, operado desde 1968 (ANGELAKIS et al., 2018) e ampliado em 2002 (HARTLEY et al., 2019; LAHNSTEINER et al., 2019).

- Gestão integrada de águas residuárias, que se baseia na adoção conjunta de sistemas centralizados e descentralizados de esgotamento sanitário nos ambientes urbanos. Atualmente, em geral, nas regiões metropolitanas os esgotos são coletados e tratados em sistemas centralizados e afastados, dificultando a reinserção desses efluentes (como água de reúso) no ciclo urbano da água, por questões logísticas. Trata-se de uma tarefa complexa e economicamente inviável, a implantação de sistema de distribuição de água duplo em regiões urbanizadas. Nesse contexto, Angelakis et al. (2018) afirmam que, no futuro, o planejamento para implantação de sistemas descentralizados de coleta e tratamento de esgotos favorecerão o reúso de água, pela proximidade entre a estação produtora de água de reúso e o usuário, que muitas vezes é o próprio gerador. Assim, os tomadores de decisão devem incluir no planejamento das cidades, a operação integrada de sistemas centralizados e descentralizados.

- Gestão integrada de águas e águas residuárias, que aborda a água como uma só, independentemente da sua fonte. No contexto internacional a água é vista, cada vez mais, como uma só (one water), que descreve todas as formas de água. 0 conceito da one water refere-se basicamente à união entre os departamentos de água e esgoto, que atualmente são separados nas principais instituições de água e esgoto do mundo. Ao unificá-los, Angelakis et al. (2018) afirmam que é possível desenvolver soluções mais ponderadas, racionais e econômicas para atender às necessidades futuras de água. No Brasil, em 2019, a até então Agência Nacional de Águas (atualmente Agência Nacional de Águas e Saneamento Básico) lançou a campanha \#AáguaÉumaSó, que tem o objetivo de alertar a sociedade para a importância da gestão dos recursos hídricos, de forma atenta à conservação da água e do meio ambiente, ao mesmo tempo em que se busca atender às necessidades dos diversos usuários. Nesse sentido, a ANA apresenta uma visão mais global, além da integração entre os setores de água e esgoto, levando em consideração todo o ciclo hidrológico da água, suas diferentes fontes, quantidade e qualidade e a integração entre os domínios estaduais e da união.

- A articulação entre o tratamento avançado de esgotos e a prática de dessalinização em megacidades localizadas nas regiões costeiras oferece uma oportunidade adicional para usos de água que requerem maior qualidade, como o potável e o industrial. Angelakis et al. (2018) sugerem que operacionalmente, o efluente da estação de tratamento avançado pode ser combinado com a água dessalinizada para pós-tratamento, de forma a atender padrões de qualidade de água mais elevados (abastecimento doméstico, por exemplo). Inclusive, Lahnsteiner et al. (2018) afirmam que não parece haver razão para que o reúso potável de água (principalmente o direto) não se torne uma opção de gestão de água comum e amplamente utilizada nos próximos 5 a 10 anos.

É importante observar como o debate internacional se encontra em estágio bem mais avançado sobre os desafios e tendências relacionados ao reúso de água. Diante dos diversos aspectos apresentados, o processo de institucionalização e sistematização da prática de reúso parece distante da realidade brasileira. Porém é necessário dar os primeiros passos (SANTOS e VIEIRA, 2020), à semelhança de exemplos como a SANASA, a SABESP, a COMPESA e a EMBASA (conforme apresentado na NT01), e outros. A EMBASA foi responsável pela contratação e elaboração de um importante projeto de avaliação de potencialidades de reúso de água no estado da Bahia que, de maneira geral, inspirou a elaboração desse conjunto de Notas Técnicas, como forma de apresentar uma metodologia de aplicação de estudo de potencial regional de reúso de água para outras regiões do país.

Nesse estudo, aspectos relevantes como a 
capacitação continuada e a implantação e operação de projeto piloto podem ser grandes aliados para a transposição de muitos desses obstáculos. A capacitação continuada deve ser implementada para toda a hierarquia envolvida nos projetos de reúso, para os potenciais usuários de maneira geral e até mesmo para a sociedade participativa. $O$ projeto piloto tem funções específicas de permitir o desenvolvimento de uma experiência prática prévia à implantação de projetos definitivos, além de, a partir da publicação de dados transparentes, criar um elo de confiança com os demais envolvidos (produtores, consumidores, reguladores, fiscalizadores e sociedade).

$\mathrm{Na}$ Figura 1, apresenta-se o fluxograma que envolve os principais desafios relacionados à prática de reúso de água no Brasil, destacados no Quadro 1, assim como a relação entre eles, os principais atores envolvidos nos aspectos de capacitação continuada, e a implantação e operação de projetos piloto.

\section{Figura 1: Fluxograma com os principais desafios distribuídos entre o projeto piloto e os atores envolvidos na capacitação continuada}



Fonte: Elaborado pelos autores.

De maneira transversal aos desafios apresentados no Quadro 1 e no fluxograma da Figura 1, destaca-se a necessidade da sistematização da análise de viabilidade econômica dos projetos de reúso de água, que atualmente é segmentada. Os projetos de reúso de água, com todos os seus desafios, não podem ser analisados somente sob a ótica da viabilidade econômica das empresas de saneamento. A análise deve ser sistêmica, envolvendo outros setores da sociedade que se beneficiarão com um maior suprimento de água, mesmo que o projeto não indique viabilidade direta para as empresas de saneamento. Formas de compensação do caixa destas empresas devem ser consideradas em situação em que a prática do reúso não se viabilize, sobretudo nas pequenas localidades expostas à insegurança hídrica.

\section{CAPACITAÇÃO CONTINUADA}

No Brasil, o termo "capacitação" tem forte relação com o aprimoramento de técnicas operacionais, para garantia de melhores desempenhos nas atividades realizadas. No setor 
do saneamento, em geral, o termo é associado à operação de unidades que compõem os serviços de abastecimento de água e esgotamento sanitário, tais como redes (de abastecimento de água e de coleta de esgoto), estações elevatórias (de água e de esgoto), reservatórios, adutoras, captações, estações de tratamento de água e de tratamento de esgoto, entre outros. Em inglês, o termo "capacitação" é traduzido como "capacity building", onde "building" refere-se à uma atividade que requer "construção".

Nesse contexto, observa-se uma diferença de entendimento entre o termo adotado no Brasil (menos abrangente) e o internacionalmente adotado (mais abrangente). O termo "capacity building", admitido como pano de fundo do presente texto, revela um processo pelo qual indivíduos e organizações obtêm, aprimoram e incorporam conhecimentos, habilidades, e ferramentas necessários para a realização de atividades com competência e participações mais marcantes no processo construtivo e na apreensão de conceitos.

Diante do exposto, os autores adotam o termo "capacitação continuada" como forma de abranger gestores e tomadores de decisão, operadores de sistemas de produção e de aplicação da água de reúso, além da sociedade civil como sociedade participativa na construção do cenário de reutilização regional de água em novos empreendimentos no Brasil.

\section{Gestores e tomadores de decisão}

A figura do gestor está intimamente relacionada ao binômio liderança e responsabilidade. Uma boa gestão é fundamental para a garantia do funcionamento adequado de uma determinada instituição ou da prestação de um serviço. No caso das instituições, os gestores são aqueles que ocupam os cargos de liderança e são responsáveis pelas tomadas de decisão; no caso da prestação de serviços de saneamento, no Brasil, essa gestão é realizada por empresas conhecidas como "prestadoras de serviço", conforme amplamente discutido na NT02. Elas apresentam regras, metodologias, métricas, roteiros, critérios, diretrizes e orientações para a execução dos serviços com o objetivo de garantir a saúde e o bem-estar da população, além da proteção ambiental. Segundo Santos e Vieira (2020), a Entidade Reguladora dos Serviços de Água e Resíduos de Portugal (ERSAR) designa essas empresas como "entidades gestoras", exatamente ressaltando a responsabilidade da gestão além daquela de prestação de serviços.

Os oito desafios expostos no Quadro 1 estão diretamente relacionados às empresas gestoras de saneamento e aos seus respectivos gestores.

Os Desafios 1, 2 e 8 estão relacionados com a visão atribuída à gestão como um todo, de que os esgotos são resíduos a serem coletados, tratados e dispostos. Já em 2012, Tchobanoglous (2012) afirmava que a água residuária não era mais vista, no contexto internacional, como um resíduo para disposição, mas uma fonte renovável e recuperável de água de abastecimento, recursos e energia. É nesse ponto que a capacitação continuada de gestores se deve apoiar, ao alavancar a transformação da cultura. Estações de tratamento de esgotos bem concebidas, projetadas, construídas e operadas são, certamente, responsáveis pelo alcance de melhores desempenhos, essencialmente necessários tanto para a proteção da saúde pública e do meio ambiente, como para a condução de ações exitosas de reúso de água. $\mathrm{O}$ aumento dos índices de cobertura com serviços de esgotamento sanitário deve ser planejado em função de critérios técnicos e socioeconômicos que podem ser discutidos, elaborados, definidos e aplicados no contexto da capacitação de gestores, para que saibam como lidar responsavelmente com o ciclo urbano da água.

Sobre a transparência das prestadoras de serviços de saneamento básico em relação aos dados dos serviços prestados, segundo o princípio constitucional da publicidade, conhecido somente como "Princípio da Publicidade", os dados qualitativos e quantitativos de operação de ETEs são de caráter público. Trata-se de um dos princípios da administração pública que tem como finalidade mostrar que o poder público deve agir com a maior transparência possível, para que a sociedade tenha o amplo conhecimento de todas as suas atuações e decisões. Essa publicização de dados leva, naturalmente, ao alcance de melhores desempenhos operacionais de ETEs, valoriza, consequentemente, a confiança do usuário/consumidor e favorece a inserção científica na construção de diálogos mais atuais e mais alinhadas com os avanços internacionais.

Nesse contexto de "transparência", o Desafio 3 também é despertado, no sentido de se levar um conhecimento técnico à sociedade civil como um todo. Além disso, a Política Nacional de Educação Ambiental (PNEA), instituída pela Lei 9.795/1999, indica que instituições como as prestadoras de 
serviços de saneamento (públicas ou privadas) devem promover a educação ambiental e o engajamento da sociedade na conservação, recuperação e melhoria do meio ambiente; e a sociedade deve manter atenção permanente à formação de valores, atitudes e habilidades que propiciem a atuação individual e coletiva voltada para a prevenção, a identificação e a solução de problemas ambientais (BRASIL, 1999).

A ausência de regulamentação e os entraves burocráticos, abordados nos Desafios 4 e 5, devem ser abrangidos pela capacitação continuada de forma a promover um desenvolvimento do setor, com um debate mais moderno dando garantia de segurança e responsabilizando as partes envolvidas. Prestadoras de serviços e órgãos reguladores e fiscalizadores necessitam de articulações e interações mais dinâmicas e diretas, conduzidas por especialistas técnicos, no sentido de elaborarem e aplicarem documentos reguladores que favoreçam a sistematização da prática de reúso de maneira rápida e com menos burocracia, mas com garantia de segurança.

Os estudos de viabilidade técnica, que representam o Desafio 6, são essenciais para a implantação exitosa de infraestruturas que envolvem a prática de reúso de água. Assim, os gestores devem ser orientados para "como esses estudos devem ser realizados" e a importância deles no contexto completo. É importante que no nível de gestão haja planejamento para designação de recursos financeiros e humanos para esses tipos de estudos.

O Desafio 7 trata dos riscos epidemiológicos que também devem ser abordados e conduzidos no âmbito da capacitação de gestores. Conforme já mencionado anteriormente, os estudos de avaliação de risco, com diferentes metodologias, são conduzidos pela área técnica, mas são essenciais para as tomadas de decisão por parte dos gestores. A construção desse conhecimento é de grande relevância para que as tomadas de decisão sejam adequadas para cada caso. Projetos de reúso de água não devem ser aplicados sem estudos de avaliação de risco de contaminação microbiológica, mesmo que simplificados (ISO, 2020; REBELO, 2018).

São os gestores que tomam as decisões e, dessa forma, para que essas sejam assertivas e com mais baixos riscos de erros, as informações devem ser todas bem produzidas e os riscos devem ser estimados e baseados em experiência ou conhecimento acumulados, onde informações incompletas e sem precisão podem levar a erros catastróficos. De acordo com Drucker (2014), as decisões não podem ser confundidas com boas intenções. Para que sejam de fato "decisões", devem ser poucas, que fazem a diferença, com um planejamento de implementação efetivo e com pessoas designadas para cada tarefa.

\section{Operadores de sistemas de produção e de uso, fornecimento ou distribuição de água de reúso}

Inicialmente, destaca-se que as empresas, entidades de classe, instituições públicas e privadas devem promover programas destinados à capacitação dos trabalhadores, visando a melhoria e o controle efetivo sobre o ambiente de trabalho, bem como sobre as repercussões do processo produtivo no meio ambiente (BRASIL, 1999). Novamente, chama-se a atenção para a definição mais global do termo "capacitação continuada", que envolve a construção do conhecimento.

A capacitação continuada de operadores de sistemas de produção e fornecimento de água de reúso é relacionada principalmente aos desafios 2 e 7 destacados no Quadro 1. Em geral, a baixa qualidade operacional (Desafio 2) é imputada somente à operação. Conforme destacado por Moraes et al. (2020), quando o eixo concepçãoprojeto-implantação-operação não é bem alinhado e bem conduzido, o baixo desempenho operacional é atribuído ao fim da linha, isto é, à operação. Entretanto, é importante destacar que a operação de sistemas de saneamento básico no Brasil, especificamente de esgotamento sanitário, sofre com a negligência das etapas anteriores de concepção, projeto e implantação nos seguintes principais aspectos, que devem ser abordados na capacitação continuada de gestores e tomadores de decisão:

- Falta de estudo de concepção para definição do projeto que mais se adequa às características locais;

- Adoção de tecnologias de tratamento inadequadas à região, em função de: condições climáticas desfavoráveis; complexidade operacional para um quadro técnico de nível inferior; e elevado consumo de energia elétrica que leva a operações mais onerosas;

- Utilização de equipamentos com materiais frágeis e de mais baixo custo, como consequência de uma cultura relacionada ao serviço de esgotamento sanitário ser 
menos importante do que 0 de abastecimento de água;

- Falta de planejamento e de investimento em manutenção de equipamentos que o ambiente agressivo das ETEs danifica com mais rapidez;

No caso específico dos operadores, a grande lacuna encontra-se na falta de conhecimento técnico teórico para o entendimento e a operação adequada no contexto da prática. Nesse sentido, a capacitação continuada de operadores deve favorecer essa união entre os conceitos práticos e teóricos para o alcance de bons desempenhos.

Em 2006, o governo federal, no âmbito do então Ministério das Cidades e do Programa de Modernização do Setor Saneamento, implantou a Rede Nacional de Capacitação e Extensão Tecnológica em Saneamento Ambiental (ReCESA), que tinha como propósito, reunir, articular e integrar um conjunto de instituições e entidades com o objetivo de promover 0 desenvolvimento institucional do setor de saneamento, mediante soluções de capacitação, intercâmbio técnico e extensão tecnológica, com abrangência em sistemas de abastecimento de água, esgotamento sanitário, drenagem de águas pluviais urbanas e resíduos sólidos (ReCESA, 2008). A Rede foi dividida em núcleos regionais para as regiões Nordeste, Sul, Sudeste e CentroOeste, para oferecimento de cursos gratuitos de capacitação para operadores de sistemas de saneamento, com uma abordagem pedagógica específica para esse público.

A proposta pedagógica da ReCESA buscava uma conexão entre o "saber fazer" e o "saber científico". Naquela época, a proposta se mostrava inovadora, mantendo-se atual nos dias de hoje e ainda com as mesmas dificuldades para a sua implantação. Essas dificuldades são inerentes aos aspectos culturais e aos paradigmas do setor saneamento no Brasil. Apesar de exitoso, o programa perdeu forças e deixou de ser aplicado, principalmente por questões financeiras.

O resgate do contexto da ReCESA é altamente aderente ao conteúdo da presente Nota Técnica, que sugere uma capacitação continuada, baseada em abordagem semelhante para dois grupos: 1) operadores dos sistemas de produção de água de reúso; 2) operadores dos sistemas de aplicação da água de reúso nas suas diferentes modalidades. De maneira simplificada, o primeiro grupo deve se esmerar para produzir uma água de reúso com a qualidade definida para a modalidade designada; e o segundo, somente pode aplicá-la na modalidade e no cenário licenciado ou autorizado.

Como já discutido nesse conjunto de Notas Técnicas, o risco de contaminação microbiológica (Desafio 7) é intrínseco à prática de reúso e essa responsabilidade é de fundamental importância para garantia da segurança dos envolvidos. Um empreendimento de reúso que foi dimensionado para um determinado cenário/modalidade leva em consideração a qualidade da água produzida e do cenário de uso. Neste caso, o risco é avaliado considerando-se essas especificidades. Portanto, uma água produzida para lavagem de ruas, em geral requer uma qualidade inferior àquela produzida para irrigação de laranjeiras. Dessa forma, a água produzida para um empreendimento licenciado e autorizado para a prática de reúso na lavagem de rua deve atender a qualidade demandada e não pode ser utilizada para a irrigação de laranjeiras. Ainda, no caso das laranjeiras, uma água que irriga a plantação por equipamento de aspersão apresenta um risco maior de contaminação dos envolvidos, do que a que irriga por gotejamento. Assim, ressalta-se que a responsabilidade do trabalho deve ser destacada na capacitação continuada de operadores.

\section{Sociedade civil}

A sociedade civil pode e deve participar das decisões relacionadas à gestão de recursos hídricos e saneamento, já que, de acordo com a Organização das Nações Unidas (ONU), a água é um direito humano fundamental (UN, 2010) e o Objetivo do Desenvolvimento Sustentável $n \div 6$ (ODS.6) garante que a disponibilidade e a gestão sustentável da água e do saneamento devem ser asseguradas para todos (UN, 2015). No Brasil, tanto a antiga Lei do Saneamento (Lei 11.445/200), como o novo Marco Legal do Saneamento (Lei 14.026/2020) determinam que a gestão do saneamento básico deve ser participativa, de forma a não só envolver a sociedade, como fomentar a sua participação nos processos de formulação de políticas, de planejamento e de avaliação dos serviços de saneamento básico (BRASIL, 2007; BRASIL, 2020). Ainda, a Política Nacional de Recursos Hídricos (PNRH), instituída pela Lei 9433/1997, define os Comitês de Bacias Hidrográficas como um importante instrumento que permite a participação dos usuários das águas sob seus domínios e das entidades civis de recursos 
hídricos com atuação comprovada na bacia (BRASIL, 1997).

Nesse sentido, essa participação pode ser direta ou indireta. A participação direta, refere-se aos representantes da sociedade civil em ambientes de planejamento e deliberação, tais como audiências públicas e comitês de bacias hidrográficas, com atuação e impactos diretos. A participação indireta refere-se ao cidadão comum, que mesmo de maneira indireta é afetado pelas decisões tomadas sem o seu conhecimento. Ambos os cenários primam pela participação democrática nos espaços de gestão de recursos hídricos e saneamento, com fins de justiça socioambiental (BERTOLDI e ROSA, 2019).

A participação direta da sociedade (por representação) está relacionada a todos os Desafios descritos no Quadro 1 e na Figura 1, considerando-se o conceito da gestão participativa no planejamento e nas decisões técnico-políticas envolvidas na gestão de recursos hídricos e saneamento.

Na discussão apresentada no presente texto, o objetivo principal em termos de desafios relacionados à capacitação da sociedade civil aborda principalmente a participação indireta. Trata-se de uma sociedade que precisa se engajar e se conscientizar sobre os aspectos atuais e futuros relacionados à água, por meio da construção de uma sociedade inteligente em termos de água (WE, 2020). No Brasil, a PNEA (BRASIL, 1999) aborda a promoção da educação ambiental em todos os níveis de ensino e o engajamento dessa sociedade na conservação, recuperação e melhoria do meio ambiente, além de estimular a construção de uma sociedade ambientalmente equilibrada.

O foco aqui não é abordar a efetividade dessa participação e sim relacioná-la com os desafios já descritos, no âmbito do planejamento e da sistematização da prática de reúso de água no Brasil. É nesse sentido que se sugere que os Desafios 3 e 7 estejam mais alinhados com a capacitação continuada dessa sociedade civil que participa indiretamente do tema. No caso do Desafio 3, é preciso abordar de maneira ampla a questão da disponibilidade hídrica real e da sua escassez em função dos aspectos de crescimento populacional, aumento da demanda por água, poluição acentuada das reservas hídrica e mudanças climáticas. Já o Desafio 7 deve ser alcançado nessa capacitação de forma a apresentar o risco inerente à prática, porém com transmissão de segurança para minimizar os efeitos naturais da rejeição psicológica. Conforme destacado por Santos e Vieira (2020), essa rejeição pode ser entendida por "Fator Eca", que em inglês é abordado como "Factor Yuck" e referese diretamente ao "nojo".

Destaca-se ainda que a engenharia brasileira não vem fazendo esse papel de maneira adequada e que essa abordagem deve acompanhar a evolução da tecnologia da informação, das ciências sociais, das metodologias pedagógicas e dos diferentes objetos de capacitação atualmente disponíveis para o despertar do interesse e do aprendizado. O tema deve ser abordado em todos os níveis de ensino nos diferentes ambientes educacionais, por todos os meios de comunicação social, nos setores empresariais e sempre, como linguagem específica e atualizada (BRASIL, 1999).

\section{PROJETO PILOTO}

Mukherjee e Jensen (2020) apresentam uma ampla discussão sobre 0 êxito dos empreendimentos de reúso de água e consideram a prévia implantação e operação de escala piloto, aspectos relevantes para coleta de dados e informações (quantitativas, qualitativas e econômica), assim como para a comunicação transparente com o público e agências governamentais, gestoras e de gerenciamento de risco.

Cumpre ressaltar que o Brasil possui uma relevante experiência na condução de projetos piloto na área de saneamento básico, adquirida ao longo de 10 anos de implementação e desenvolvimento do Programa de Pesquisa em Saneamento Básico (PROSAB) desenvolvido no âmbito da Financiadora de Estudos e Projetos (FINEP), por meio do qual foram construídos e operados vários parques experimentais de tecnologias de saneamento em todo território nacional. O PROSAB foi de grande importância para a aplicação/inovação tecnológica no país, ao desenvolver projetos reais, em escalas de bancada e de demonstração, de forma a atender as necessidades e as peculiaridades nacionais, com tecnologias de mais fácil aplicabilidade, baixo custo de implantação, operação e manutenção, e com resultados diretos para a melhoria das condições de vida da população brasileira. Toda a sua história, que abrange as áreas de abastecimento de água, esgotamento sanitário, gestão de resíduos sólidos urbanos, e gestão de águas pluviais está contada nas suas mais de 3 dezenas de publicações que podem ser acessadas 
no website da FINEP.

O projeto piloto, que por si só aponta para a garantia de êxito no empreendimento (Desafio 6), configura-se não somente como uma etapa importante, mas também estratégica no contexto da avaliação do potencial regional de reúso de água e da sistematização da prática. A sua operação é capaz de fornecer resultados preliminares relacionados aos principais entraves e aos benefícios, além de poder ser de grande relevância para o alinhamento da aceitação por parte da população e para o estabelecimento dos reais custos de produção da água de reúso. Ressalta-se que a sua aplicabilidade está diretamente relacionada ao porte do projeto, embora seja sempre recomendada.

No presente texto, a abordagem do projeto piloto se dá alinhada aos empreendimentos de grande porte, com recortes espaciais definidos nos âmbitos de região hidrográfica, bacia hidrográfica e limite administrativo estadual, onde muitos cenários podem ser apresentados, estudados e extrapolados. Assim, na definição das principais características do projeto piloto, em empreendimentos de grande porte deve-se abranger, conforme abordado na NT03, a listagem de áreas prioritárias, o levantamento e localização das ofertas e demandas, a avaliação de distâncias entre potenciais ofertas e demandas, além de permitir a realização do estudo preliminar de custo.

As áreas prioritárias são as regiões que possuem elevado potencial para a implantação do projeto piloto, onde são levantados os tipos de demanda (entre as diferentes modalidades de reúso abordadas na NT01), onde são analisadas as distâncias entre a localização das ETEs até à área escolhida, e onde o custo pode ser preliminarmente composto. Para tanto, sugere-se uma avaliação estratégica para cada projeto piloto aventado no planejamento, com elevado nível de detalhamento e consideração de características locais, viabilidade, tipos de transporte, possíveis impactos sociais, econômicos e ambientais, além de demais fatores que interfiram na replicação do modelo. Trata-se de um planejamento similar ao de concepção abordado na NT02, que deve apresentar projetos comparáveis entre si de forma a facilitar a adoção da concepção básica a ser implantada e operada no formato de projeto piloto. Assim, para a sua definição e instalação, apresentam-se no Quadro 2 os fatores que devem ser levados em consideração em relação à água de reúso: i) quantidade de água de reúso demandada; ii) qualidade relacionada ao uso pretendido; iii) localização dos reservatórios de armazenamento e/ou abordagem econômica de transporte (caminhão ou adução) até o consumidor; iv) estruturação da tarifa de reúso; e v) articulação para aceitação da população.

Diante dos aspectos relacionados a implantação e operação de projeto piloto anteriormente à condução do(s) empreendimento(s) definitivo(s), observa-se a aderência do tema com os Desafios 2, 5, 6, 7 e 8 destacados no Quadro 1 e na Figura 1, conforme já relatado de maneira geral no Quadro 2. A operação do projeto piloto com objetivos claros e definidos permite um ganho de qualidade operacional (Desafio 2) e facilita a superação dos entraves burocráticos (Desafio 5), na medida em que, com transparência (Desafios 8), permite a articulação entre as prestadoras de serviço, os órgãos fiscalizadores e os reguladores, além de outros parceiros. Ainda, como uma importante ferramenta do estudo de viabilidade (Desafio 6), o projeto piloto permite uma avaliação mais aprofundada dos riscos microbiológicos de contaminação (Desafio 7) e se mostra um importante elo de confiança entre os envolvidos de maneira geral.

Por fim, destaca-se que o projeto piloto ainda pode ser um importante elemento de capacitação continuada para todas os atores envolvidos (gestores e tomadores de decisão, operadores de sistemas de reúso de água e sociedade civil), conforme demonstrado no fluxograma da Figura 1. $E$, especificamente no caso do público representado por operadores, possibilita ainda a elaboração de manuais de operação que considerem uma proposição de revisão e implantação de rotinas operacionais mais detalhadas e adequadas à prática de reúso, bem como indica a inclusão de fatores relevantes ao alcance de melhores práticas operacionais das ETEs e/ou EPARs.

Classicamente, o manual de operação é um documento integrante dos projetos executivos de ETE no Brasil. De acordo com Jordão e Pessoa (2017), o manual de operação de ETE é o documento técnico que indica os objetivos do tratamento, os parâmetros de qualidade a serem alcançados no efluente tratado, as eficiências relativas aos principais componentes e constituintes do esgoto, as regras ou instruções para operação das diversas unidades e equipamentos eletromecânicos, a forma de se avaliar a eficiência alcançada, o plano de amostragem e as respectivas análises do esgoto 
ao longo do tratamento, a forma de apresentar relatórios periódicos e resultados alcançados, o plano de manutenção preventiva das principais unidades da ETE, recomendações relativas ao quadro de pessoal técnico e administrativos e outras eventuais indicações.

Nesse contexto, o manual de operação indica como conduzir as atividades operacionais e de controle para que os objetivos de qualidade sejam alcançados. Para tanto, em função de diversos fatores como desgaste das unidades, maior conhecimento das práticas por parte dos funcionários ao longo da operação, flutuação de operadores, conhecimento real das características do esgoto afluente, evolução do acréscimo de vazão ao longo dos anos até o alcance da vazão máxima, entre outros, sugere-se que o manual de operação seja revisto e que cursos de capacitação sejam planejados e implementados à equipe. Nos casos de ETEs consideradas para potenciais ofertas de água de reúso, há uma nova variável a ser introduzida na confecção do manual de operação. E a experiência da operação do projeto piloto pode ser fundamental para a construção desse conteúdo.

Ressalta-se ainda a importância do entendimento de que o manual de operação, neste caso, não deve ser encarado como um documento estático e estanque. Este documento deve ser atualizado com dados reais de operação sempre que a equipe operacional da ETE ou da EPAR perceba a necessidade da sua revisão. Essa atualização deve ser realizada em concomitância com atividades de capacitação continuada.

\section{CONSIDERAÇÕES FINAIS}

Nesta Nota Técnica 04 apresentam-se os principais desafios e tendências para o futuro da sistematização da prática de reúso de água no Brasil. Para que essa institucionalização seja alcançada, a gestão de saneamento, recursos hídricos e áreas afins, dos ambientes urbanos e rurais, deve levar em consideração aspectos relevantes e integrados, tanto de infraestruturação como de gestão eficiente e planejada. Neste contexto, destacam-se os seguintes:

- Conhecimento, caracterização e avaliação das principais demandas de água nas áreas urbanas e nas áreas rurais (integradas ou não ao ambiente urbano);
- Gerenciamento das ofertas de água de abastecimento, por sistemas convencionais (de captação superficial e subterrânea) para os diferentes fins;

- Alcance dos serviços de esgotamento sanitário e de abastecimento de água universalizados;

- Concepção, elaboração de projeto, implantação e operação adequados de Estações de Produção de Água de Reúso a partir do efluente da Estação de Tratamento de Esgoto;

- Em regiões litorâneas, e quando possível, avaliação da integração de unidades de dessalinização da água do mar com outras fontes alternativas de água, com definição de rotas de tubulação entre as plantas de dessalinização, tratamento de esgoto, produção de água de reúso e reservatório;

- Planejamento e implantação de reservatórios estratégicos de água de reúso para diferentes fins;

- Integração do transporte da água de reúso por caminhão pipa e/ou tubulação;

- Condução da capacitação continuada de gestores, de operadores e da sociedade civil;

- Definição de metas e métodos para redução dos impactos de rejeição psicológica por parte dos usuários;

- Gestão eficiente das prestadoras de serviços de saneamento básico, considerando 0 conceito da gestão integrada de águas e águas residuárias (one water) e o planejamento;

- Gestão integrada de sistemas centralizados e descentralizados de abastecimento de água e esgotamento sanitário para fins de reúso;

- Operação de projetos piloto com objetivos de consolidação da prática, capacitação, relação transparente com o usuário e auxílio na composição tarifária.

Por fim, a sistematização da prática de reúso de água deve ser conduzida de maneira gradual e planejada, com foco nos fatores mais relevantes e características particulares de cada região de estudo, a partir de uma gestão integrada e eficiente entre os setores envolvidos. 


\section{Quadro 2: Fatores relacionados à implantação do projeto piloto em empreendimentos de} grande porte

\begin{tabular}{|c|c|}
\hline Desafio & Descrição \\
\hline $\begin{array}{l}\text { Quantidade de água } \\
\text { de reúso demandada }\end{array}$ & $\begin{array}{l}\text { A demanda hídrica para diferentes fins é um fator relevante neste contexto de } \\
\text { implantação e operação do projeto piloto. Nesse sentido, é importante analisar a } \\
\text { quantidade de água demandada, na região do entorno, em situações que que poderiam } \\
\text { ser beneficiadas com o projeto. Atender quantitativamente as demandas na fase de } \\
\text { operação do projeto piloto se configura como uma importante ferramenta de } \\
\text { aprendizagem e interiorização de dificuldades inerentes à prática. }\end{array}$ \\
\hline $\begin{array}{l}\text { Qualidade da água } \\
\text { de reúso }\end{array}$ & $\begin{array}{l}\text { Alinhada à abordagem fit-for-purpose (ajustada ao uso), a qualidade da água de reúso } \\
\text { deve ser definida em relação ao uso final pretendido, adequado a cada situação, tendo } \\
\text { em vista a proteção da saúde pública e do meio ambiente. Destaca-se aqui a avaliação } \\
\text { da necessidade de otimização da ETE para atendimento da qualidade requerida, } \\
\text { lembrando que somente } 34 \% \text { das ETEs em operação no Brasil apresentam } \\
\text { desempenho de remoção de matéria orgânica superior a } 80 \% \text { e somente } 9 \% \\
\text { apresentam algum tipo de desinfecção em seus fluxogramas (ANA, 2020b). A qualidade } \\
\text { deve ser categorizada de acordo com o tipo de uso e com o nível de restrição (restrito } \\
\text { e irrestrito), conforme indicado no Programa Interáguas (INTERÁGUAS, 2017). Essa } \\
\text { categorização possui o objetivo de redução do risco de contaminação microbiológica } \\
\text { associada à prática (SANTOS et al., 2020). }\end{array}$ \\
\hline $\begin{array}{l}\text { Reservação e/ou } \\
\text { Transporte da água } \\
\text { de reúso }\end{array}$ & $\begin{array}{l}\text { Um dos grandes entraves nos estudos de avaliação de potencial de reúso é a estratégia } \\
\text { a ser adotada em relação à necessidade de reservação da água de reúso e/ou o } \\
\text { transporte direto até o consumidor final. A implantação de reservatórios pode ser para } \\
\text { a finalidade de redução das distâncias entre as ETEs e o consumidor final, assim como } \\
\text { o de armazenamento em função da sazonalidade das demandas. Nesse caso, ainda } \\
\text { se discute a pós desinfecção para se evitar o recrescimento de microrganismos (ISO, } \\
2020 ; \text { APA, 2019). Já o transporte direto pode ser estabelecido através de adutoras ou } \\
\text { de caminhões-pipa (NT03). Araujo et al. (2017) desenvolveram uma metodologia para } \\
\text { o cálculo do custo do transporte da água de reúso em caminhão pipa com o objetivo de } \\
\text { avaliar as distâncias máximas viáveis. }\end{array}$ \\
\hline
\end{tabular}

Estruturação da tarifa de reúso

Aceitação da população

Trata-se de uma tarefa complexa e sensível, mas necessária para tornar os
empreendimentos viáveis economicamente. Embora sejam muitas as suas vantagens técnicas, nem sempre a prática de reúso de água é a melhor solução para a escassez hídrica. A operação do projeto piloto apresenta-se como uma grande aliada, ao facilitar a composição desse custo, levando em consideração os custos operacionais, de capital e de reposição, descritos na NT02. Ressalta-se, entretanto, que a depender do quadro de escassez hídrica da região, o reúso de água pode ser a única solução de abastecimento e, nesse caso, agrega-se mais uma variável à composição do custo, tornando a tarefa ainda mais complexa. Esse cenário pode demandar a imposição de uma tarifa extremamente elevada, que quando comparada à cobrança pelo uso da água pode limitar a implantação da prática de reúso. Segundo Melo et al. (2020), o valor da cobrança pelo uso da água no Brasil é em torno de 0,02 a $0,03 \mathrm{R} \$ / \mathrm{m}^{3}$, nas bacias hidrográficas com políticas de cobrança já instaladas (NT03). Diante dos baixos valores atribuídos, um dos objetivos dessa cobrança, que é fomentar o uso racional da água não é alcançado (OCDE, 2017). Nesse contexto de elevado grau de escassez hídrica, Israel se destaca por reutilizar atualmente $87 \%$ do esgoto tratado no país, com a imposição de tarifas elevadas para a água de reúso, apesar de mais baixas do que as tarifas para água superficial e dessalinizada (ARAUJO et al., 2017).

Conforme já mencionado, a implantação e operação do projeto piloto pode ter forte relação com a minimização do impacto da rejeição psicológica (Factor Yuck) do usuário da água de reúso. Nesse caso, a transparência das ações, principalmente por parte das instituições de produção e oferta de água de reúso, é que vai alavancar a confiança do usuário. Nesse contexto, Harris-Lovett et al. (2015) afirmam que a operação de projetos piloto, aliada a uma linha de comunicação com a população, pode ser um bom caminho para o sucesso na aceitação pública. Países como Singapura investiram na aproximação da população com o tema, criando centros de visitação da NEWater, como instalações piloto, e atualmente $30 \%$ da demanda de água no país é suprida com água de reúso, de maneira exitosa (LEFEBVRE, 2018). Ressalta-se a importância de um programa de envolvimento da população com o projeto piloto, com o objetivo de transmitir confiança e segurança. 


\section{REFERÊNCIAS}

ANA. AGÊNCIA NACIONAL DE ÁGUAS E SANEAMENTO BÁSICO. Conjuntura dos recursos hídricos no Brasil 2020: informe anual / Agência Nacional de Águas. Brasília: ANA, 2020a.

ANA. Agência Nacional de Águas (Brasil). Atlas esgotos: atualização da base de dados de estações de tratamento de esgotos no Brasil. Brasília, DF: ANA, 2020b.

ANGELAKIS, A. N.; ASANO, T.; BAHRI, A.; JIMENEZ, B. E.; TCHOBANOGLOUS G. Water Reuse: From Ancient to Modern Times and the Future. Frontiers Environmental Science, v. 6, n. 26, 2018.

APA. AGÊNCIA PORTUGUESA DO AMBIENTE. Guia para reutilização de água - usos não potáveis. Lisboa: APA, 2019.

ARAUJO, B. M.; SANTOS, A. S. P.; PAVAN, F. Comparativo econômico entre o custo estimado do reúso de efluente de ETE para fins industriais não potáveis em comparação ao valor da água potável para a região sudeste do Brasil. Exatas \& Engenharias, v. 7, n. 17, 2017.

ARENA, C.; GENCO, M.; MAZZOLA, M. R. Environmental Benefits and Economical Sustainability of Urban Wastewater Reuse for Irrigation-A CostBenefit Analysis of an Existing Reuse Project in Puglia, Italy. Water, v. 12, n.10, p. 2926, 2020.

BASTOS, R. K. X.; KIPERSTOK, A.; CHERNICHARO, C. A. L.; FLORENCIO, L.; MONTEGGIA, L. O.; SPERLING, M.; AISSE, M. M.; BEVILAQUA, P. D.; PIVELI, R. P. Subsídios à regulamentação do reúso de águas no Brasil - Utilização de esgotos sanitários tratados para fins agrícolas, urbanos e piscicultura.

Revista DAE, v. 177, n. 122, 2008.

BRASIL. Lei no 14.026, 15 de julho de 2020. Atualiza o marco legal do saneamento básico e altera as Leis $\mathrm{n}^{\circ}$ 9.984/2020, no 10.768/2003, no 11.107/2005, no 11.445/2007, no 12.305/2010, no 13.089/2015, no 13.5029/2017. Diário Oficial da União, Brasília, 15 de julho de 2020.

BRASIL. Lei no. 11.445, de 5 de janeiro de 2007. Estabelece as diretrizes nacionais para o saneamento básico e para a política federal de saneamento básico. Brasília, DF. 2007.

BRASIL. Lei no 9.795, de 27 de abril de 1999. Dispõe sobre a educação ambiental, institui a Política Nacional de Educação Ambiental e dá outras providências. Brasília, DF, 1999.
BRASIL. Lei no $\mathbf{9 . 4 3 3}$, de 8 de janeiro de 1997. Institui a Política Nacional de Recursos Hídricos, cria o Sistema Nacional de Gerenciamento de Recursos Hídricos. Diário Oficial da União. Brasília, DF. 1997.

BERTOLDI, M. R. ; ROSA, R. G. . A concretização do direito à informação ambiental: o acesso à informação para a efetividade da cidadania socioambiental brasileira. Revista de Direito Econômico e Socioambiental, v. 10, p. 233-257, 2019.

CHERNICHARO, C. A.; RIBEIRO, T. B.; PEGORINI, E. S.; POSSETTI, G. R. C.; MIKI, M. K.; SOUZA, S. N. Contribuição para o aprimoramento de projeto, construção e operação de reatores UASB aplicados ao tratamento de esgoto sanitário - Parte 1: Tópicos de Interesse. Revista DAE, v. 66, p. 5-16, 2018.

DRUCKER, P. F. Innovation and Entrepreneurship: Practice and Principles. New York: Harper \& Row, p. 277, 2014.

ESPINOSA, M.F.; SPERLING, M.; VERBYLA, M.E. Performance evaluation of 388 full-scale waste stabilization ponds systems with seven different configurations. Water Science and Technology, v. 75, n. 4, p. 916-927, 2017.

FRIJNS, J.; SMITH, H. M.; BROUWER, S.; GARNETT, K.; ELELMAN, R.; JEFFREY, P. How governance regimes shape the implementation of water reuse schemes. Water v. 8, p. 605, 2016.

HARRIS-LOVETT, S. R.; BINZ, C.; SEDLAK, D. L.; KIPARSKY, M.; TRUFFER, B. Beyond User Acceptance: A Legitimacy Framework for Potable Water Reuse in California. Environmental Science Technology, v. 49, n. 13, p. 7552-7561, 2015.

HARTLEY, K.; TORTAJADA, C.; BISWAS, A.K. A forma model concerning policy strategies to build public acceptance of potable water reuse. Journal of environmental management, v. 250, 2019.

INTERÁGUAS - PROGRAMA DE DESENVOLVIMENTO DO SETOR ÁGUAS.

Elaboração de proposta de plano de ações para instituir uma política de reúso de efluente sanitário tratado no Brasil. Produto III - Critérios de qualidade de água. Brasília. 2017.

ISO. INTERNATIONAL ORGANIZATION FOR STANDARDIZATION. ISO 16075-1:2020 - Guidelines for treated wastewater use for irrigation projects - Part 1: The basis of a reuse project for irrigation, International Organization for Standardization, Geneva. 2020. 
JORDÃO, E. P e PESSÔA, C. A. Tratamento de Esgotos Domésticos. 7. ed. Rio de Janeiro: ABES, 2017.

KHAN, S.J.; ANDERSON, R. Potable reuse: experiences in Australia. Environmental Science and Health, v. 2, p. 55-60, 2018.

LAHNSTEINER, J.; VAN RENSBURG, P.; ESTERHUIZEN, J. Direct potable reuse - a feasible water management option. Water reuse and desalination, v. 8, n. 1, 2018.

LEFEBVRE, O. Beyond NEWater: an insight into Singapore's water reuse prospects. Environmental Science \& Health, v. 2, p. 26-31, 2018.

LIMA, M.; ARAUJO, B. M.; SOARES, S. R. A.; SANTOS, A. S. P.; VIEIRA, J. M. P.; Water reuse potential for irrigation in Brazilian hydrographic regions. Water Supply, 2020. Disponível em: https://doi.org/10.2166/ws.2020.280. Acesso em: 20 de fev. 2021.

MELO, M. C.; SANTOS, A. S. P.; SANTOS, N. A. P.; ARAÚJO, B. M.; OLIVEIRA, J. R. S.; CAMPOS, A. R. Evaluation of potential use of domestic treated effluents or irrigation in areas subject to conflicts over water use in Paracatu River Basin. Caminhos da Geografia (UFU. Online), v. 21, p. 52-63, 2020.

MORAES, D. L.; SANTOS, A. S. P.; BILA, D. M.; SILVA JÚNIOR, L. C. S.; ARAUJO, B. M. Análise comparativa de parâmetros hidráulicos para dimensionamento de tecnologias em Estações de Tratamento de Esgoto. Revista Internacional de Ciências, v. 10, p. 22-41, 2020.

MUKHERJEE, M.; JENSEN, O. A comparative analysis of the development of regulation and technology uptake in the US and Australia. Safety Science, v. 121, p. 514, 2020.

OCDE. Cobranças pelo uso de recursos hídricos no Brasil: Caminhos a seguir. Éditions OCDE, Paris, 2017.

OMS. ORGANIZAÇÃO MUNDIAL DE SAÚDE. Sanitation safety planning manual for safe use and disposal of wastewater, greywater and excreta.

Geneva: World Health Organization. 2016.

ReCESA. Rede de Capacitação e Extensão Tecnológica em Saneamento Ambiental. Processos de tratamento de esgotos: guia do profissional em treinamento: nível 1 / Ministério das Cidades.
Secretaria Nacional de Saneamento Ambiental. Brasília, DF, 2008.

REBELO, A. Reutilização de água: Abordagem para o desenvolvimento de práticas de reutilização de água. In: Atas do 14ํㅡㄹ Congresso da Água, Évora. 2018.

SANCHEZ-FLORES, R.; CONNER, A.; KAISER, R. A. The regulatory framework of reclaimed wastewater for potable reuse in the United States. International Journal of Water Resources Development. 2016.

SANTOS, A. S. P.; GONÇALVES, R. F.; MELO, M. C.; LIMA, M. A. M.; ARAUJO, B. M. Uma análise crítica sobre os padrões de qualidade de água de uso e de reúso no Brasil. Revista Sustinere, v. 8, n. 2, p. 437 462,2020

SANTOS, A. S. P.; LIMA, M. A. M; RAMOS, L. T. A.; PEREIRA, C. B.; SOARES, S. R. A.; MELO, M. C. Capacidade de reúso de efluentes de Estações de Tratamento de Esgoto na Bacia Hidrográfica do Paraíba do Sul. Semioses (Rio de Janeiro), v. 12, p. 16-33, 2018.

SANTOS, A. S. P.; VIEIRA, J. M. P. Reúso De Água Para O Desenvolvimento Sustentável: Aspectos de regulamentação no Brasil e em Portugal. Revista Eletrônica de Gestão e Tecnologias Ambientais, v. 8, p. 50-68, 2020.

TCHOBANOGLOUS, G. New directions for wastewater treatment in the 21st century. In: Flotation 2012 Proceedings 6th International Conference on Flotation for Water and Wastewater Systems, New York, NY, International Water Association. 2012.

UN. United Nations. General Assembly Resolution $A / R E S / 64 / 292$. 2010. The human right to safe drinking water and sanitation. Disponível em: https://www.un.org/en/ga/search/view_doc.asp?symbol =A/RES/64/292. Acesso em: 1 de jul. 2020.

UN. United Nations. General Assembly Resolution A/RES/70/1. Transforming our world: the $\mathbf{2 0 3 0}$ Agenda for Sustainable Development. 2015. Disponível em:

https://www.un.org/en/development/desa/population/mi gration/generalassembly/docs/globalcompact/A_RES_7 0_1_E.pdf. Acesso em: 1 de jul. 2020.

\section{WATER EUROPE. A water smart society for a} successful post COVID19 recovery plan. Bruxelas: WE, 2020. Disponível em: https://watereurope.eu/wpcontent/uploads/2020/04/A-Water-Smart-Society-for-apost-covid19-recovery-plan.pdf. Acesso em: 9 dez. de 20 